\title{
Diagnosis of cardiac surgery-associated acute kidney injury: differential roles of creatinine, chitinase 3-like protein 1 and neutrophil gelatinase-associated lipocalin: a prospective cohort study
}

Jorien De Loor ${ }^{1 *}$, Ingrid Herck², Katrien Francois ${ }^{3}$, Astrid Van Wesemael $^{4}$, Lieve Nuytinck ${ }^{5}$, Evelyne Meyer ${ }^{1 \dagger}$ and Eric A. J. Hoste $2,6+$

\begin{abstract}
Background: A common and serious complication of cardiac surgery prompting early detection and intervention is cardiac surgery-associated acute kidney injury (CSA-AKI). Urinary chitinase 3-like protein 1 (UCHI3L1) was found to predict AKI associated with critical illness in adults. Our aims were therefore to evaluate whether UCHI3L1 can also be used to predict AKI associated with elective cardiac surgery in adults, and to compare this predictive ability with that of urinary neutrophil gelatinase-associated lipocalin (UNGAL), more frequently assessed early serum creatinine (SCr) measurements, and various two-biomarker panels.
\end{abstract}

Methods: This was a single-centre prospective cohort study at the eight-bed cardiac surgery ICU of Ghent University Hospital. AKI was diagnosed and classified according to the Kidney Disease|Improving Global Outcomes definitions for the diagnosis and staging of AKI, which are based on SCr and urine output (UO). Of the 211 enrolled elective cardiac surgery patients, we included 203 patients who had no AKI pre-operatively and at time of post-operative ICU admission (t1) in the primary endpoint analysis (i.e. AKI stage $\geq 1$ within $48 \mathrm{~h}$ after $\mathrm{t1}$ ), while 210 patients without AKI stage $\geq 2$ pre-operatively and at $\mathrm{t} 1$ were included in the secondary endpoint analysis (i.e. AKI stage $\geq 2$ within $12 \mathrm{~h}$ after $\mathrm{t} 1$ ). Systemic and/or urine concentrations of $\mathrm{Cr}, \mathrm{CHI} 3 \mathrm{~L} 1$ and NGAL were measured more frequently than $\mathrm{SCr}$ in routine early post-operative ICU practice. UO was monitored hourly in the ICU.

Results: Within $48 \mathrm{~h}$ after $\mathrm{t} 1,46.8 \%$ of the patients had developed AKI (70.5\% stage 1, 20.0\% stage 2 and $9.5 \%$ stage 3). In the early post-operative period, only SCr was a good predictor of AKI within $48 \mathrm{~h}$ after $\mathrm{t} 1$ (primary endpoint). SCHI3L1 combined with either UCHI3L1 or UNGAL was a good predictor of AKI stage $\geq 2$ within $12 \mathrm{~h}$ after $\mathrm{t} 1$ (secondary endpoint). However, $\mathrm{SCr}$ and its absolute difference from pre-operative to early measures after surgery outperformed these combinations.

Conclusions: We found that more frequent assessment of the functional biomarker $\mathrm{SCr}$ in the early post-operative ICU period (first $4 \mathrm{~h}$ ) after elective cardiac surgery in adult patients had good to excellent predictive value for CSA-AKI,

\footnotetext{
*Correspondence: Jorien.DeLoor@UGent.be

†Evelyne Meyer and Eric A. J. Hoste contributed equally to this work and acted as equivalent co-senior authors

${ }^{1}$ Laboratory of Biochemistry, Department of Pharmacology, Toxicology

and Biochemistry, Faculty of Veterinary Medicine, Ghent University,

Salisburylaan 133, 9820 Merelbeke, Belgium

Full list of author information is available at the end of the article
} 
indicating that routine $\mathrm{SCr}$ assessment must become more frequent in order to detect AKI more early. This performance was in contrast with the inadequate predictive value of the urinary renal stress or damage biomarkers UCHI3L1 and UNGAL.

Keywords: Acute kidney injury, Biological markers, Chitinase, Cardiac surgery, Lipocalins

\section{Background}

Cardiac surgery-associated acute kidney injury (CSA$\mathrm{AKI}$ ) is a common and serious complication of cardiac surgery [1]. Depending on its severity and differences in both baseline characteristics and type of cardiac surgical procedure, the range of incidence of CSA-AKI is between 3.0 and $50.0 \%$ when applying Kidney Disease|Improving Global Outcomes (KDIGO)-like criteria [2-6]. CSA-AKI treated with renal replacement therapy (RRT) presents post-operatively in $2.0-6.0 \%$ of cardiac surgery patients $[5,7,8]$, of which 1 out of 2 die in hospital [5]. Importantly, also when the injury is mild, CSA-AKI is independently associated with significant effects on early [i.e. hospital or 30-day (d)] mortality $[9,10]$.

Risk for CSA-AKI is increased by the presence of established pre-operative [e.g. increased serum creatinine (SCr)] and peri-operative (e.g. low cardiac output) factors that increase susceptibility to AKI $[11,12]$. Moreover, potentially important modifiable intra-operative susceptibilities are the type of cardiac surgical technique and, if cardiopulmonary bypass [CPB; synonym: extracorporeal circulation (ECC)] is used, the characteristics of the perfusion technique [13]. Early CSA-AKI occurs within $7 \mathrm{~d}$ after the cardiac surgical procedure and is directly related to it [14]. CSA-AKI more than 1 week but within $30 \mathrm{~d}$ after the cardiac surgical procedure is mainly related to another exposure that presents as a complication of the cardiac surgical procedure (e.g. sepsis) [14].

Only recently the term 'acute kidney stress' (AKS) was proposed to describe the pre-injury phase that leads to AKI [15]. Biomarkers, or 'measurable and quantifiable biological parameters' [16], that respond to AKS open new horizons in regard to the prediction and early detection of emerging AKI. These biomarkers serve as surrogate measurements, estimating renal cell perfusion, function or metabolism [15]. As regulator of the iron metabolism, neutrophil gelatinase-associated lipocalin (NGAL) measured in blood or urine represents a way to monitor initial damage [17], which was confirmed in more than 7000 paediatric and adult patients who underwent cardiac surgery [18-20]. Recently, our group demonstrated the role of urinary chitinase 3 -like protein 1 (UCHI3L1) as predictor of AKI in an adult general intensive care unit (ICU) cohort, with a performance similar to that of UNGAL [21].

Higher systemic concentrations of CHI3L1 have been independently associated with the presence of coronary artery disease, seeming a quantitative indicator of disease progression as well [22]. Additionally, it was shown that in patients with type 1 and type 2 diabetes mellitus higher systemic concentrations of CHI3L1 were associated with progressing vascular damage in the kidneys, as assessed by the level of albuminuria [22]. It seems plausible that low-grade inflammation and endothelial dysfunction progressing to micro- and macrovascular complications account for higher systemic concentrations of CHI3L1. Besides a marker of chronic inflammation, systemic CHI3L1 is a marker of acute inflammation as well [23]. Cardiac surgery and the use of CPB have a critical role in inducing the systemic inflammatory response syndrome leading to CSA-AKI. Consequently, SCHI3L1 can be proposed as a potential AKI risk factor.

The objectives of this study were:

(a) To evaluate whether UCHI3L1 can be used to predict occurrence of AKI in adult patients who underwent elective cardiac surgery,

(b) To compare this predictive ability with that of UNGAL, a well-known biomarker of tubular damage, and that of more frequently assessed early measurements of $\mathrm{SCr}$, a routine biomarker of kidney dysfunction,

(c) To evaluate whether combining either two urinary renal stress or damage biomarkers, or a systemic kidney dysfunction biomarker and a urinary renal stress or damage biomarker can improve the predictive ability for CSA-AKI,

(d) To evaluate whether combining SCHI3L1 with either a systemic kidney dysfunction biomarker or a urinary renal stress or damage biomarker can improve the predictive ability for CSA-AKI.

\section{Methods}

This research is reported according to the STrengthening the Reporting of OBservational studies in Epidemiology (STROBE) Statement (Additional file 1: Fig. S1) [24].

\section{Defining AKI}

AKI was diagnosed and classified according to the KDIGO definitions for the diagnosis and staging of AKI, which are based on $\mathrm{SCr}$ and urine output (UO) (Additional file 2: Fig. S2) [25]. 


\section{Study patients}

In this single-centre cohort study, we prospectively enrolled patients who were admitted to the eight-bed cardiac surgery ICU of Ghent University Hospital from May 2012 till February 2014. The inclusion and exclusion criteria of the study are incorporated in the flow diagram in Fig. 1.

\section{Primary endpoint}

The primary endpoint of the current study was the development of AKI stage $\geq 1$ within $48 \mathrm{~h}$ after $\mathrm{t} 1$. Reference $\mathrm{SCr}$, representing baseline $\mathrm{SCr}$, was defined as the lowest $\mathrm{SCr}$ value within the last 3 months (mo) prior to enrolment (lowest of history SCr value(s) and pre-operative $\mathrm{SCr}$ ). In our cohort $30.0 \%$ of the patients had only the pre-operative $\mathrm{SCr}$ value available. In $49.3 \%$ the lowest history $\mathrm{SCr}$ was lower than or equal to the pre-operative $\mathrm{SCr}$, while in $20.7 \%$ the pre-operative $\mathrm{SCr}$ was lower than the lowest history SCr. The details for calculation of UO are outlined by our group [21]. Note that UO was registered hourly in the ICU only.

\section{Secondary endpoint}

The secondary endpoint was AKI stage $\geq 2$ within $12 \mathrm{~h}$ after $\mathrm{t} 1$.

\section{Ethics approval and consent to participate}

The Ethical Committee of Ghent University Hospital approved this study (Belgian Registration Number of the study: B670201213147). All patients or their legally authorized representatives provided written informed consent. We respected the Declaration of Helsinki and the Good Clinical Practice Guidelines.

\section{Prospective sample and data collection}

The first collection of blood and urine was after the induction of anaesthesia and before the start of surgery [time $0(\mathrm{t} 0)$ on the day of surgery $\left.\left(\mathrm{d}_{\text {surgery }}\right)\right]$. The rest of the specimens $(n=7)$ were collected post-operatively, starting at ICU admission (t1) and then at 2 hours (h)

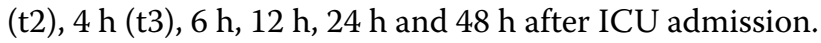
If the patient was discharged to the Midcare unit before $24 \mathrm{~h}$ or $48 \mathrm{~h}$, those samples were collected there. Whenever possible, the routine collection times were followed [at 4 PM on the first post-operative day $\left(\mathrm{d}_{1 \text { post-op }}\right)$ and at $6 \mathrm{AM}$ on the second post-operative day $\left.\left(\mathrm{d}_{2 \text { post-op }}\right)\right]$. The sample collection times for a fictional patient who underwent surgery in the morning are outlined on the timeline in Additional file 3: Fig. S3A, while those for a fictional patient who underwent surgery in the afternoon are outlined on the timeline in Additional file 4: Fig. S3B.

These paired blood and urine samples were collected by standard methods and centrifuged by standard protocols, as described previously by our group [21]. Serum and urine supernatants were stored at $-80{ }^{\circ} \mathrm{C}$ and thawed at room temperature immediately prior to analysis. Clinical data needed to complete the individual clinical research files (Additional file 5: Table S1) were extracted from the hospital records by study coordinators. Note that Additional file 5 contains Tables S1, S2, S3, S4A, B, C, D and the legends of Figures S1, S2, S3A, B, S4, S5, S6. Samples were anonymized as were clinical data. All technicians were blinded to clinical data.

\section{Biomarker analysis and single-biomarker diagnostic test possibilities}

The CHI3L1 analysis was performed in-house. We measured the concentration of CHI3L1 by a sandwich enzyme-linked immunosorbent assay (ELISA) technique (DC3L10, R\&D Systems, Minneapolis, MN, USA). Analyses performed externally were $\mathrm{Cr}$ and UNGAL. The Cobas c502 measured the concentration of $\mathrm{Cr}$ by a kinetic rate-blanked Jaffé assay (commercial reagents, Roche Diagnostics, Basel, Switzerland), whereas the Modular P measured the concentration of UNGAL by a particle-enhanced turbidimetric immunoassay (ST0013CA, BioPorto, Hellerup, Denmark). All details were recently described [21], except for the standard sample dilution scheme used in the CHI3L1 ELISA, which is presented in Additional file 5: Table S2. For blood samples that were collected at routine collection times, a $\mathrm{SCr}$ concentration was already available in the hospital records. Based on the temporal relationship of the predictive value of UNGAL for CSA-AKI [19], we measured this biomarker at $\mathrm{t} 1$ and $\mathrm{t} 3$ only.

Besides UCHI3L1 and UNGAL, we also evaluated UCHI3L1 and UNGAL corrected for urine dilution by using the ratio to $\mathrm{UCr}$ as diagnostic test. Besides $\mathrm{SCr}$, we also evaluated $\Delta \mathrm{SCr}_{\mathrm{tx} \text {-t0 }}$ as diagnostic test, representing the absolute change in $\mathrm{SCr}$ between $\mathrm{SCr}_{\mathrm{tx}}$ and $\mathrm{SCr}_{\mathrm{t} 0}$. The most recent $\mathrm{SCr}$ value recorded prior to surgery was considered as $\mathrm{SCr}_{\mathrm{t} 0}$.

\section{Defining acute tubular damage and subclinical AKI}

Following the recommendations of de Geus et al., acute tubular damage was defined as a CSA-NGAL score of 2 or greater; either as $\mathrm{UNGAL}_{\mathrm{t} 1}$ or $\mathrm{UNGAL}_{\mathrm{t} 3} \geq 150 \mathrm{ng} / \mathrm{ml}$ or as $\Delta \mathrm{UNGAL}_{\mathrm{t} 3-\mathrm{t} 1}>100 \mathrm{ng} / \mathrm{ml}$ with $\mathrm{UNGAL}_{\mathrm{t} 3} \geq 125 \mathrm{ng} /$ $\mathrm{ml}$ [26]. Subclinical AKI was defined when there was acute tubular damage (according to the 'de Geus criteria') and absence of AKI according to the KDIGO definition.

\section{Defining good and excellent biomarkers}

An area under the receiver operating characteristics curve (AUC-ROC) of 0.750 or greater was considered to represent a good biomarker, whereas an AUC-ROC of 


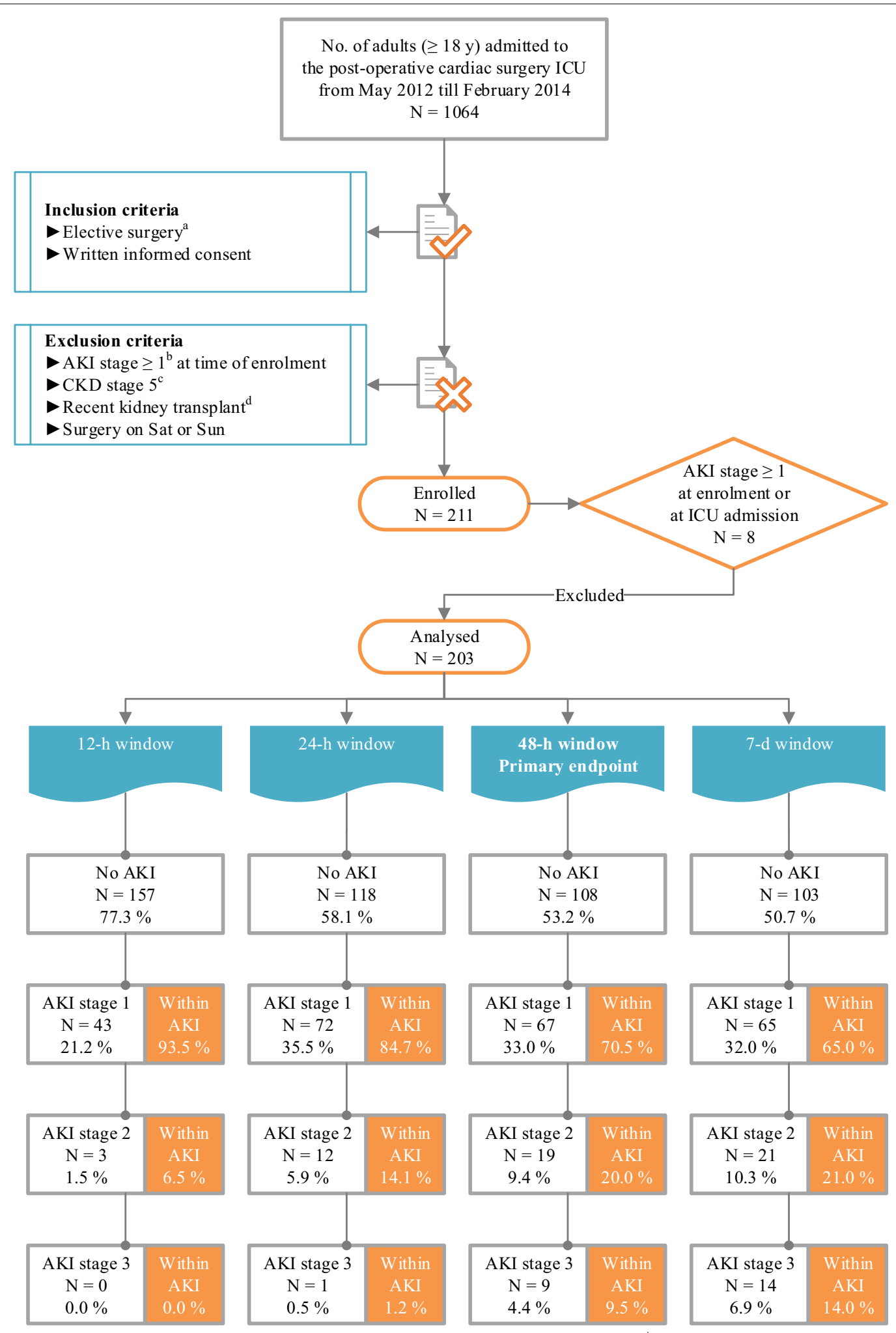

Fig. 1 Flow diagram of patient enrolment and primary endpoint analysis. ${ }^{2}$ Planned $\geq 4 \mathrm{~h}$ in advance. ${ }^{\mathrm{b}} \mathrm{KDIGO}$ definitions for the diagnosis and staging of AKI, which are based on SCr and UO [25]. ${ }^{C} \mathrm{KDOQ}$ definitions for the diagnosis and staging of CKD [40]. ${ }^{\mathrm{d}} \leq 3$ mo before. AKI acute kidney injury, CKD chronic kidney disease, $d$ day, $h$ hour, ICU intensive care unit, KDIGO Kidney Disease|Improving Global Outcomes, KDOQI Kidney Disease Outcomes Quality Initiative, mo month, No. number, Sat Saturday, SCr serum creatinine, Sun Sunday, UO urine output, y year 
0.900 or greater was considered to represent an excellent biomarker [27].

\section{Statistical analysis}

The principal statistical analysis was based on comparison of the AUC-ROCs of UCHI3L1 with those of UNGAL, more frequently assessed early measurements of SCr, and various two-biomarker panels for predicting both defined endpoints. It was performed in MedCalc 15.2.1 (MedCalc Software, Oostende, Belgium). The unpaired comparison of a variable between two independent samples was done in SPSS 22 (IBM, Armonk, NY, USA). Categorical variables were analysed with Fisher's exact or the Chi-square test, and continuous variables with the nonparametric Mann-Whitney $U$ test. Additionally, we calculated the $95 \%$ confidence interval (CI) for a proportion using the Wilson procedure without a correction for continuity [28, 29]. For all analyses, two-sided $P$ values $<0.05$ were considered statistically significant. All details and a description of how the biomarkers were introduced into the statistical programs are provided in our previous work [21].

\section{Results}

Incidence of the primary endpoint, characteristics of the patients and procedures, and short-term patient outcomes The flow of patients during the study is illustrated in Fig. 1. The initial enrolment cohort consisted of 211 patients. In the primary endpoint analysis, 8 patients who already had AKI stage $\geq 1$ at to $(n=3)$ or $\mathrm{t} 1$ were excluded, resulting in a total number of 203 patients for analysis. Within $48 \mathrm{~h}$ after t1, 95 patients (46.8\%) had developed AKI: 67 (70.5\%) were classified as stage $1,19(20.0 \%)$ as stage 2 and $9(9.5 \%)$ as stage 3. Three patients received RRT starting

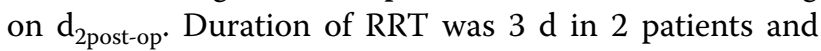
$14 \mathrm{~d}$ in 1 patient. The flow of patients over different diagnostic windows for AKI is illustrated in Fig. 1. The limited extent to which the UO criterion identified AKI patients is illustrated in Additional file 6: Fig. S4. Median time to AKI diagnosis was $12.2 \mathrm{~h}$ [interquartile range (IQR) 7.2$18.4 \mathrm{~h}$. Subclinical AKI, which was missed by KDIGO, occurred in $5.1 \%$ of the patients (Fig. 2).

Table 1 summarizes the characteristics of the patients and procedures at baseline. Compared with patients without AKI, patients who developed AKI within $48 \mathrm{~h}$ after $\mathrm{t} 1$ were older; had a higher body mass index (BMI); a lower eGFR; a higher prevalence of diabetes mellitus (DM) type 2; a higher predicted operative mortality, which was estimated by the simple additive European system for cardiac operative risk evaluation (EuroSCORE); more combined surgical procedures; and a higher prevalence of diuretic treatment at home.
Peri-operative characteristics of the patients and procedures are provided in Additional file 5: Table S3. In comparison with patients without AKI, patients who developed AKI within $48 \mathrm{~h}$ after t1 had a higher Sepsisrelated Organ Failure Assessment (SOFA) score; a higher white blood cell (WBC) count; a higher serum C-reactive protein (CRP) concentration; a more positive fluid balance; a higher number of plasma units that were transfused; and a higher prevalence of vasopressor, milrinone and diuretic treatment.

AKI patients had a longer ICU and hospital length of stay (LOS) (Table 1).

\section{Incidence of the secondary endpoint}

In the secondary endpoint analysis, 1 patient who already had AKI stage $\geq 2$ at t0 was excluded, resulting in a total number of 210 patients for analysis. Within $12 \mathrm{~h}$ after t1, 5 patients $(2.4 \%)$ had developed AKI stage $\geq 2$ : all $5(100 \%)$ were classified as stage 2 . The flow of patients over different diagnostic windows for AKI stage $\geq 2$ is illustrated in Additional file 7: Fig. S5.

\section{Biomarker performances for prediction of the primary endpoint}

In the early post-operative period, only the functional biomarker SCr was a good predictor of AKI within $48 \mathrm{~h}$ after $\mathrm{t} 1$, showing the highest AUC-ROC at t3 (0.792; 95\% CI 0.728-0.847; Fig. 3). The information in Fig. 3 is summarized in numerical format in Additional file 5: Tables S4B, C and D, including also the performances of the urinary renal stress or damage biomarkers corrected for urine dilution by using the ratio to UCr. Table S4A reports the performances of the biomarkers measured at to.

\section{Biomarker performances for prediction of the secondary endpoint}

In the early post-operative period, SCHI3L1 combined with a urinary renal stress or damage biomarker, either UCHI3L1 or UNGAL, was a good predictor of AKI stage $\geq 2$ within $12 \mathrm{~h}$ after $\mathrm{t} 1$, showing the highest AUC-ROC at t2 when combined with UCHI3L1 (0.773; 95\% CI 0.708$0.829)$ and at $\mathrm{t} 3$ when combined with UNGAL (0.774; 95\% CI 0.710-0.830). However, the functional biomarkers $\mathrm{SCr}$ and $\Delta \mathrm{SCr}_{\mathrm{tx}-\mathrm{to}}$ outperformed these combinations with good to excellent performances, showing the highest AUC-ROC at $\mathrm{t} 3$ (0.857 for SCr; 95\% CI 0.801-0.902; 0.938 for $\Delta \mathrm{SCr}_{\mathrm{tx}-\mathrm{t} 0}$; $95 \%$ CI $0.860-1.000$; Fig. 3). The information in Fig. 3 is summarized in numerical format in Additional file 5: Tables S4B, C and D, including also the performances of the urinary renal stress or damage biomarkers corrected for urine dilution by using the ratio 


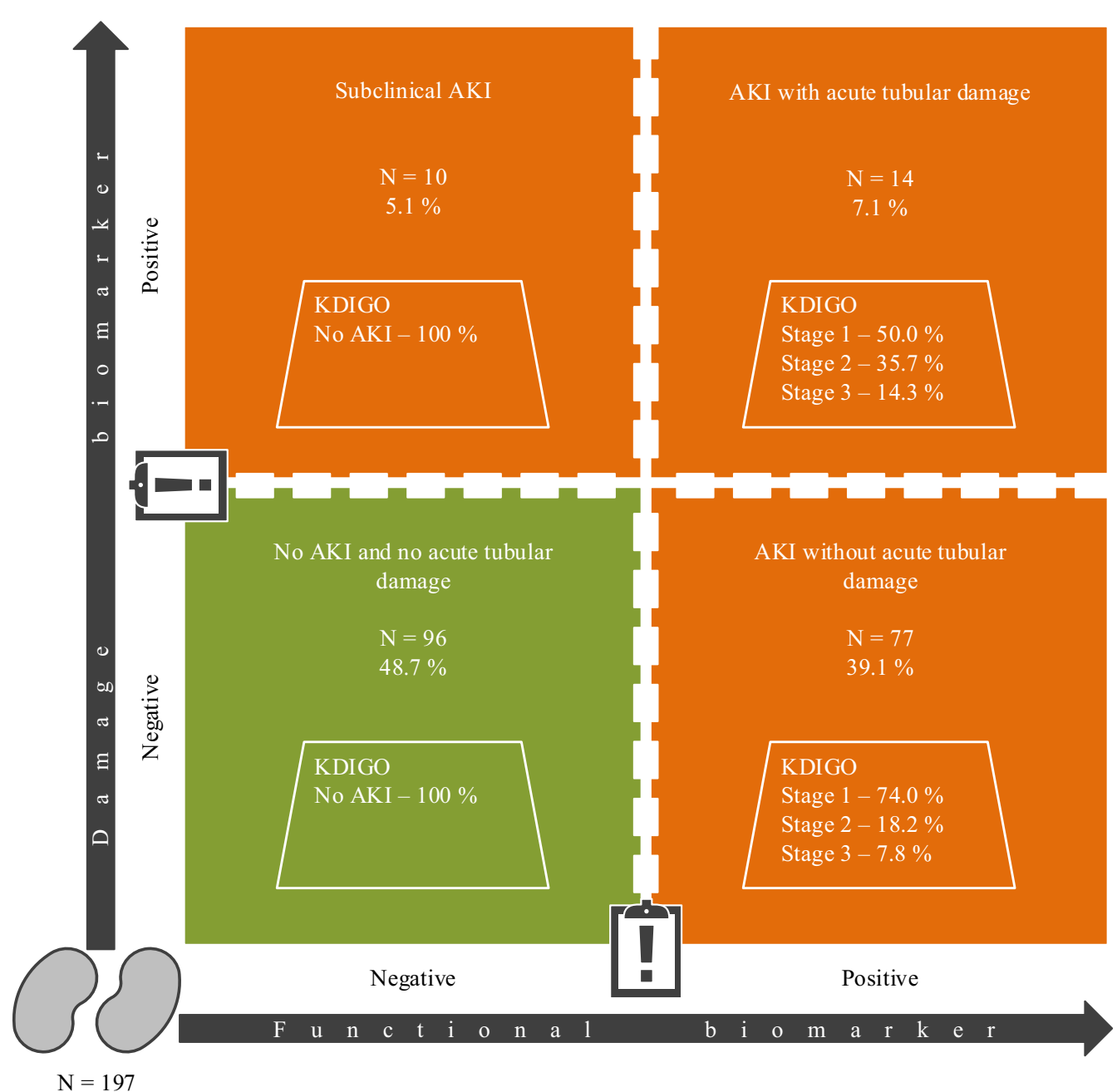

Fig. 2 Combining functional and damage biomarkers simultaneously to delineate the spectrum of AKI. Patients of the primary analysis cohort $(n=203)$ who had no $U_{N G A L}$ or $U_{N G A L}$ concentration available were excluded. Missing UNGAL ${ }_{t 1}$ occurred in 5 patients, and missing UNGAL $L_{t 3}$ in 1 patient, resulting in a total of 197 patients. Following the recommendations of de Geus et al., acute tubular damage was defined as a CSA-NGAL

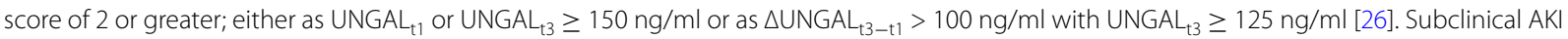
was defined when there was acute tubular damage (according to the 'de Geus criteria') and absence of AKI according to the KDIGO definition. In this way $84.6 \%$ of AKI in our specific cohort (i.e. 77/[77 + 14]) was classified as AKI without acute tubular damage. Subclinical AKI, which was missed by KDIGO, occurred in $5.1 \%$ of the patients. AKI acute kidney injury, CSA cardiac surgery-associated, $d$ day, KDIGO Kidney Disease|Improving Global Outcomes, $t 1$ time of intensive care unit admission, $t 34 \mathrm{~h}$ after intensive care unit admission, UNGAL urinary neutrophil gelatinase-associated lipocalin

to UCr. Table S4A reports the performances of the biomarkers measured at $\mathrm{t} 0$.

\section{Discussion}

We found that in adult patients who underwent elective cardiac surgery, UCHI3L1 had inadequate predictive value for CSA-AKI. This was also true for the well-known tubular damage biomarker UNGAL. In contrast, more frequent assessment of the functional biomarker $\mathrm{SCr}$ in the early post-operative ICU period (first $4 \mathrm{~h}$ ) had good to excellent predictive value for CSA-AKI.
Similar to others, our ICU routinely measures $\mathrm{SCr}$ at $\mathrm{t} 1$ and either around $\mathrm{t} 4$ (morning patient) or $\mathrm{t} 5$ (afternoon patient) in the early post-operative period. However, with $\pm 50 \%$ of AKI diagnosed before $\mathrm{t} 5$, of which $\pm 50 \%$ before $\mathrm{t} 4$, our study highlights the importance of more frequent $\mathrm{SCr}$ assessment in the first $4 \mathrm{~h}$. This aids in early AKI diagnosis and could also reveal some cases of rapid reversal of AKI (i.e. 'complete reversal of AKI by KDIGO criteria within $48 \mathrm{~h}$ of AKI onset' [30]). These findings are in accordance with those of a small retrospective study $(n=29)$ by Maciel et al. [31]. 
Table 1 Characteristics of the patients and procedures at baseline, as well as short-term patient outcomes

\begin{tabular}{|c|c|c|c|c|}
\hline $\begin{array}{l}\text { No. (\%) } \\
{[95 \% \mathrm{Cl}]}\end{array}$ & $\begin{array}{l}\text { All patients } \\
203(100) \\
{[98.1-100]}\end{array}$ & $\begin{array}{l}\text { AKI stage } \geq 1^{a} \text { within } 48 \mathrm{~h} \\
95(46.8) \\
{[40.1-53.7]}\end{array}$ & $\begin{array}{l}\text { No } A K I^{\mathrm{a}} \text { within } 48 \mathrm{~h} \\
108(53.2) \\
{[46.3-59.9]}\end{array}$ & $P$ value \\
\hline \multicolumn{5}{|l|}{ Characteristic } \\
\hline Male sex-no. (\%) [95\% Cl] & $\begin{array}{l}133(65.5) \\
{[58.7-71.7]}\end{array}$ & $\begin{array}{l}65(68.4) \\
{[58.5-76.9]}\end{array}$ & $\begin{array}{l}68(63.0) \\
{[53.6-71.5]}\end{array}$ & 0.461 \\
\hline White race-no. (\%) [95\% Cl] & $\begin{array}{l}202(99.5) \\
{[97.3-99.9]}\end{array}$ & $\begin{array}{l}95(100) \\
{[96.1-100]}\end{array}$ & $\begin{array}{l}107(99.1) \\
{[94.9-99.8]}\end{array}$ & 1.000 \\
\hline Age $^{\mathrm{b}}(\mathrm{IQR})-$ years & $70.0(61.0-76.0)$ & $74.0(65.0-80.0)$ & $67.0(58.0-75.0)$ & $<0.001$ \\
\hline $\mathrm{BMI}(\mathrm{IQR})$ & $27(24-29)$ & $27(25-31)$ & $26(23-29)$ & 0.004 \\
\hline \multicolumn{5}{|l|}{ Medical history } \\
\hline \multicolumn{5}{|l|}{ Reference renal function (IQR) } \\
\hline $\mathrm{sCr}-\mathrm{mg} / \mathrm{dl}$ & $0.90(0.75-1.05)$ & $0.99(0.81-1.16)$ & $0.82(0.70-0.95)$ & $<0.001$ \\
\hline $\mathrm{eGFR} \mathrm{CKD}$-EPI$-\mathrm{ml} / \mathrm{min} / 1.73 \mathrm{~m}^{2}$ & $82(64-94)$ & $73(54-85)$ & $87(77-97)$ & $<0.001$ \\
\hline DM-no. (\%) $[95 \% \mathrm{Cl}]$ & & & & 0.025 \\
\hline Type 1 & $\begin{array}{l}2(1.0) \\
{[0.3-3.5]}\end{array}$ & $\begin{array}{l}2(2.1) \\
{[0.6-7.4]}\end{array}$ & $\begin{array}{l}0(0.0) \\
{[0.0-3.4]}\end{array}$ & \\
\hline Type 2 & $\begin{array}{l}46(22.7) \\
{[17.4-28.9]}\end{array}$ & $\begin{array}{l}28(29.5) \\
{[21.2-39.3]}\end{array}$ & $\begin{array}{l}18(16.7) \\
{[10.8-24.8]}\end{array}$ & \\
\hline No DM & $\begin{array}{l}155(76.4) \\
{[70.1-81.7]}\end{array}$ & $\begin{array}{l}65(68.4) \\
{[58.5-76.9]}\end{array}$ & $\begin{array}{l}90(83.3) \\
{[75.2-89.2]}\end{array}$ & \\
\hline Heart failure-no. (\%) [95\% Cl] & & & & 0.252 \\
\hline NYHA class I & $\begin{array}{l}145(71.4) \\
{[64.9-77.2]}\end{array}$ & $\begin{array}{l}64(67.4) \\
{[57.4-76.0]}\end{array}$ & $\begin{array}{l}81(75.0) \\
{[66.1-82.2]}\end{array}$ & \\
\hline NYHA class II & $\begin{array}{l}36(17.7) \\
{[13.1-23.6]}\end{array}$ & $\begin{array}{l}17(17.9) \\
{[11.5-26.8]}\end{array}$ & $\begin{array}{l}19(17.6) \\
{[11.6-25.8]}\end{array}$ & \\
\hline NYHA class III & $\begin{array}{l}20(9.9) \\
{[6.5-14.7]}\end{array}$ & $\begin{array}{l}12(12.6) \\
{[7.4-20.8]}\end{array}$ & $\begin{array}{l}8(7.4) \\
{[3.8-13.9]}\end{array}$ & \\
\hline NYHA class IV & $\begin{array}{l}2(1.0) \\
{[0.3-3.5]}\end{array}$ & $\begin{array}{l}2(2.1) \\
{[0.6-7.4]}\end{array}$ & $\begin{array}{l}0(0.0) \\
{[0.0-3.4]}\end{array}$ & \\
\hline \multicolumn{5}{|l|}{ Clinical examination } \\
\hline \multicolumn{5}{|l|}{ Blood pressure $(\mathrm{IQR})-\mathrm{mm} \mathrm{Hg}$} \\
\hline Systolic & $134(122-149)$ & $132(122-150)$ & $134(120-149)$ & 0.704 \\
\hline Diastolic & $72(64-78)$ & $72(63-78)$ & $71(66-78)$ & 0.619 \\
\hline Mean & $93(85-101)$ & $92(84-102)$ & $93(86-100)$ & 0.734 \\
\hline Heart rhythm—no. (\%) [95\% Cl] & & & & 0.074 \\
\hline Atrial fibrillation & $\begin{array}{l}16(7.9) \\
{[4.9-12.4]}\end{array}$ & $\begin{array}{l}11(11.6) \\
{[6.6-19.6]}\end{array}$ & $\begin{array}{l}5(4.6) \\
{[2.0-10.4]}\end{array}$ & \\
\hline Normal sinus rhythm & $\begin{array}{l}187(92.1) \\
{[87.6-95.1]}\end{array}$ & $\begin{array}{l}84(88.4) \\
{[80.4-93.4]}\end{array}$ & $\begin{array}{l}103(95.4) \\
{[89.6-98.0]}\end{array}$ & \\
\hline $\begin{array}{l}\text { Heart rate in normal sinus rhythm (IQR)—bpm } \\
(N=187)\end{array}$ & $69(61-79)$ & $70(62-81)$ & $69(60-76)$ & 0.143 \\
\hline Distribution of ejection fraction-no. (\%) [95\% Cl] & & & & 0.531 \\
\hline$\leq 20 \%$ & $\begin{array}{l}5(2.5) \\
{[1.1-5.6]}\end{array}$ & $\begin{array}{l}4(4.2) \\
{[1.6-10.3]}\end{array}$ & $\begin{array}{l}1(0.9) \\
{[0.2-5.1]}\end{array}$ & \\
\hline $21-30 \%$ & $\begin{array}{l}3(1.5) \\
{[0.5-4.3]}\end{array}$ & $\begin{array}{l}2(2.1) \\
{[0.6-7.4]}\end{array}$ & $\begin{array}{l}1(0.9) \\
{[0.2-5.1]}\end{array}$ & \\
\hline $31-50 \%$ & $\begin{array}{l}33(16.3) \\
{[11.8-22.0]}\end{array}$ & $\begin{array}{l}16(16.8) \\
{[10.6-25.6]}\end{array}$ & $\begin{array}{l}17(15.7) \\
{[10.1-23.8]}\end{array}$ & \\
\hline$>50 \%$ & $\begin{array}{l}119(58.6) \\
{[51.7-65.2]}\end{array}$ & $\begin{array}{l}55(57.9) \\
{[47.8-67.3]}\end{array}$ & $\begin{array}{l}64(59.3) \\
{[49.8-68.1]}\end{array}$ & \\
\hline \multicolumn{5}{|l|}{ Index surgical procedure } \\
\hline EuroSCORE (IQR) & $5(3-8)$ & $6(4-9)$ & $5(2-7)$ & 0.004 \\
\hline Type of cardiac surgical procedure-no. (\%) [95\% Cl] & & & & 0.005 \\
\hline Isolated CABG & $\begin{array}{l}93(45.8) \\
{[39.1-52.7]}\end{array}$ & $\begin{array}{l}34(35.8) \\
{[26.9-45.8]}\end{array}$ & $\begin{array}{l}59(54.6) \\
{[45.2-63.7]}\end{array}$ & \\
\hline Isolated valve repair or replacement & $\begin{array}{l}55(27.1) \\
{[21.4-33.6]}\end{array}$ & $\begin{array}{l}28(29.5) \\
{[21.2-39.3]}\end{array}$ & $\begin{array}{l}27(25.0) \\
{[17.8-33.9]}\end{array}$ & \\
\hline
\end{tabular}


Table 1 continued

\begin{tabular}{|c|c|c|c|c|}
\hline $\begin{array}{l}\text { No. }(\%) \\
{[95 \% \mathrm{Cl}]}\end{array}$ & $\begin{array}{l}\text { All patients } \\
203(100) \\
{[98.1-100]}\end{array}$ & $\begin{array}{l}\text { AKI stage } \geq 1^{\text {a }} \text { within } 48 \mathrm{~h} \\
95(46.8) \\
{[40.1-53.7]}\end{array}$ & $\begin{array}{l}\text { No } A K I^{a} \text { within } 48 \mathrm{~h} \\
108(53.2) \\
{[46.3-59.9]}\end{array}$ & $P$ value \\
\hline CABG and valve repair or replacement & $\begin{array}{l}34(16.7) \\
{[12.2-22.5]}\end{array}$ & $\begin{array}{l}25(26.3) \\
{[18.5-36.0]}\end{array}$ & $\begin{array}{l}9(8.3) \\
{[4.4-15.1]}\end{array}$ & \\
\hline Aortic root & $\begin{array}{l}12(5.9) \\
{[3.4-10.0]}\end{array}$ & $\begin{array}{l}5(5.3) \\
{[2.3-11.7]}\end{array}$ & $\begin{array}{l}7(6.5) \\
{[3.2-12.8]}\end{array}$ & \\
\hline Other & $\begin{array}{l}9(4.4) \\
{[2.3-8.2]}\end{array}$ & $\begin{array}{l}3(3.2) \\
{[1.1-8.9]}\end{array}$ & $\begin{array}{l}6(5.6) \\
{[2.6-11.6]}\end{array}$ & \\
\hline ECC—no. (\%) $[95 \%$ Cl] & & & & 0.516 \\
\hline Yes & $\begin{array}{l}179(88.2) \\
{[83.0-91.9]}\end{array}$ & $\begin{array}{l}82(86.3) \\
{[78.0-91.8]}\end{array}$ & $\begin{array}{l}97(89.8) \\
{[82.7-94.2]}\end{array}$ & \\
\hline No & $\begin{array}{l}24(11.8) \\
{[8.1-17.0]}\end{array}$ & $\begin{array}{l}13(13.7) \\
{[8.2-22.0]}\end{array}$ & $\begin{array}{l}11(10.2) \\
{[5.8-17.3]}\end{array}$ & \\
\hline $\begin{array}{l}\text { Duration of ECC (IQR)—min } \\
N=179\end{array}$ & $91.5(70.8-123.3)$ & $92.0(70.3-131.3)$ & $91.5(70.3-117.8)$ & 0.527 \\
\hline $\begin{array}{l}\text { Priming volume of ECC pump (IQR)—ml } \\
N=179\end{array}$ & $1300(1200-1500)$ & $1300(1200-1500)$ & $1300(1150-1400)$ & 0.246 \\
\hline $\begin{array}{l}\text { Duration of aortic clamp during ECC (IQR)—min } \\
N=179\end{array}$ & $56.0(42.8-82.0)$ & $62.0(45.0-88.0)$ & $55.0(40.5-74.5)$ & 0.174 \\
\hline $\begin{array}{l}\text { Duration of ischaemia during ECC (IQR)—min } \\
N=179\end{array}$ & $54.0(39.0-78.0)$ & $61.0(43.0-81.0)$ & $52.0(37.8-70.5)$ & 0.164 \\
\hline Duration of surgery (IQR)-h & $4.6(3.9-5.2)$ & $4.7(3.9-5.3)$ & $4.5(3.9-5.1)$ & 0.196 \\
\hline IABP peri-operatively—no. (\%) [95\% Cl] & $\begin{array}{l}7(3.4) \\
{[1.7-6.9]}\end{array}$ & $\begin{array}{l}2(2.1) \\
{[0.6-7.4]}\end{array}$ & $\begin{array}{l}5(4.6) \\
{[2.0-10.4]}\end{array}$ & 0.452 \\
\hline \multicolumn{5}{|l|}{ Medication-no. (\%) [95\% Cl] } \\
\hline Statins & $\begin{array}{l}127(62.6) \\
{[55.7-68.9]}\end{array}$ & $\begin{array}{l}63(66.3) \\
{[56.3-75.0]}\end{array}$ & $\begin{array}{l}64(59.3) \\
{[49.8-68.1]}\end{array}$ & 0.313 \\
\hline ACE inhibitors & $\begin{array}{l}56(27.6) \\
{[21.9-34.1]}\end{array}$ & $\begin{array}{l}28(29.5) \\
{[21.2-39.3]}\end{array}$ & $\begin{array}{l}28(25.9) \\
{[18.6-34.9]}\end{array}$ & 0.638 \\
\hline ARBs & $\begin{array}{l}7(3.4) \\
{[1.7-6.9]}\end{array}$ & $\begin{array}{l}6(6.3) \\
{[2.9-13.1]}\end{array}$ & $\begin{array}{l}1(0.9) \\
{[0.2-5.1]}\end{array}$ & 0.052 \\
\hline Diuretics & $\begin{array}{l}51(25.1) \\
{[19.7-31.5]}\end{array}$ & $\begin{array}{l}36(37.9) \\
{[28.8-47.9]}\end{array}$ & $\begin{array}{l}15(13.9) \\
{[8.6-21.7]}\end{array}$ & $<0.001$ \\
\hline NSAIDs & $\begin{array}{l}4(2.0) \\
{[0.8-5.0]}\end{array}$ & $\begin{array}{l}1(1.1) \\
{[0.2-5.7]}\end{array}$ & $\begin{array}{l}3(2.8) \\
{[0.9-7.9]}\end{array}$ & 0.624 \\
\hline Corticosteroids & $\begin{array}{l}13(6.4) \\
{[3.8-10.6]}\end{array}$ & $\begin{array}{l}8(8.4) \\
{[4.3-15.7]}\end{array}$ & $\begin{array}{l}5(4.6) \\
{[2.0-10.4]}\end{array}$ & 0.390 \\
\hline Tacrolimus & $\begin{array}{l}0(0.0) \\
{[0.0-1.9]}\end{array}$ & $\begin{array}{l}0(0.0) \\
{[0.0-3.9]}\end{array}$ & $\begin{array}{l}0(0.0) \\
{[0.0-3.4]}\end{array}$ & NA \\
\hline Cyclosporine & $\begin{array}{l}2(1.0) \\
{[0.3-3.5]}\end{array}$ & $\begin{array}{l}2(2.1) \\
{[0.6-7.4]}\end{array}$ & $\begin{array}{l}0(0.0) \\
{[0.0-3.4]}\end{array}$ & 0.218 \\
\hline Aminoglycosides & $\begin{array}{l}3(1.5) \\
{[0.5-4.3]}\end{array}$ & $\begin{array}{l}1(1.1) \\
{[0.2-5.7]}\end{array}$ & $\begin{array}{l}2(1.9) \\
{[0.5-6.5]}\end{array}$ & 1.000 \\
\hline Corticosteroids intra-operatively & $\begin{array}{l}0(0.0) \\
{[0.0-1.9]}\end{array}$ & $\begin{array}{l}0(0.0) \\
{[0.0-3.9]}\end{array}$ & $\begin{array}{l}0(0.0) \\
{[0.0-3.4]}\end{array}$ & NA \\
\hline lodinated contrast $\leq 72 \mathrm{~h}$ before surgery & $\begin{array}{l}37(18.2) \\
{[13.5-24.1]}\end{array}$ & $\begin{array}{l}14(14.7) \\
{[9.0-23.2]}\end{array}$ & $\begin{array}{l}23(21.3) \\
{[14.6-29.9]}\end{array}$ & 0.275 \\
\hline \multicolumn{5}{|l|}{ Outcomes } \\
\hline RRT in ICU—no. (\%) [95\% Cl] & $\begin{array}{l}3(1.5) \\
{[0.5-4.3]}\end{array}$ & $\begin{array}{l}3(3.2) \\
{[1.1-8.9]}\end{array}$ & $\begin{array}{l}0(0.0) \\
{[0.0-3.4]}\end{array}$ & 0.101 \\
\hline ICU LOS (IQR)—d & $1(1-3)$ & $2(1-3)$ & $1(1-2)$ & $<0.001$ \\
\hline Hospital LOS (IQR)—d & $12(9-16)$ & $13(10-20)$ & $10(9-13)$ & $<0.001$ \\
\hline
\end{tabular}

$A C E$ angiotensin-converting enzyme, $A K I$ acute kidney injury, $A R B$ angiotensin-Il receptor blocker, $B M I$ body mass index, $b p m$ beats per minute, $C A B G$ coronary artery bypass grafting, Cl confidence interval, CKD-EPI Chronic Kidney Disease Epidemiology Collaboration, DM diabetes mellitus, ECC extracorporeal circulation, eGFR estimated glomerular filtration rate, EuroSCORE European system for cardiac operative risk evaluation, $h$ hour, IABP intra-aortic balloon pump, ICU intensive care unit, $I Q R$ interquartile range, KDIGO Kidney Disease|Improving Global Outcomes, LOS length of stay, min minute, no. number, NSAID nonsteroidal anti-inflammatory drug, NYHA New York Heart Association, RRT renal replacement therapy, SCr serum creatinine, UO urine output

${ }^{a} \mathrm{KDIGO}$ definitions for the diagnosis and staging of AKI, which are based on $\mathrm{SCr}$ and UO

b Determined at the day of surgery 


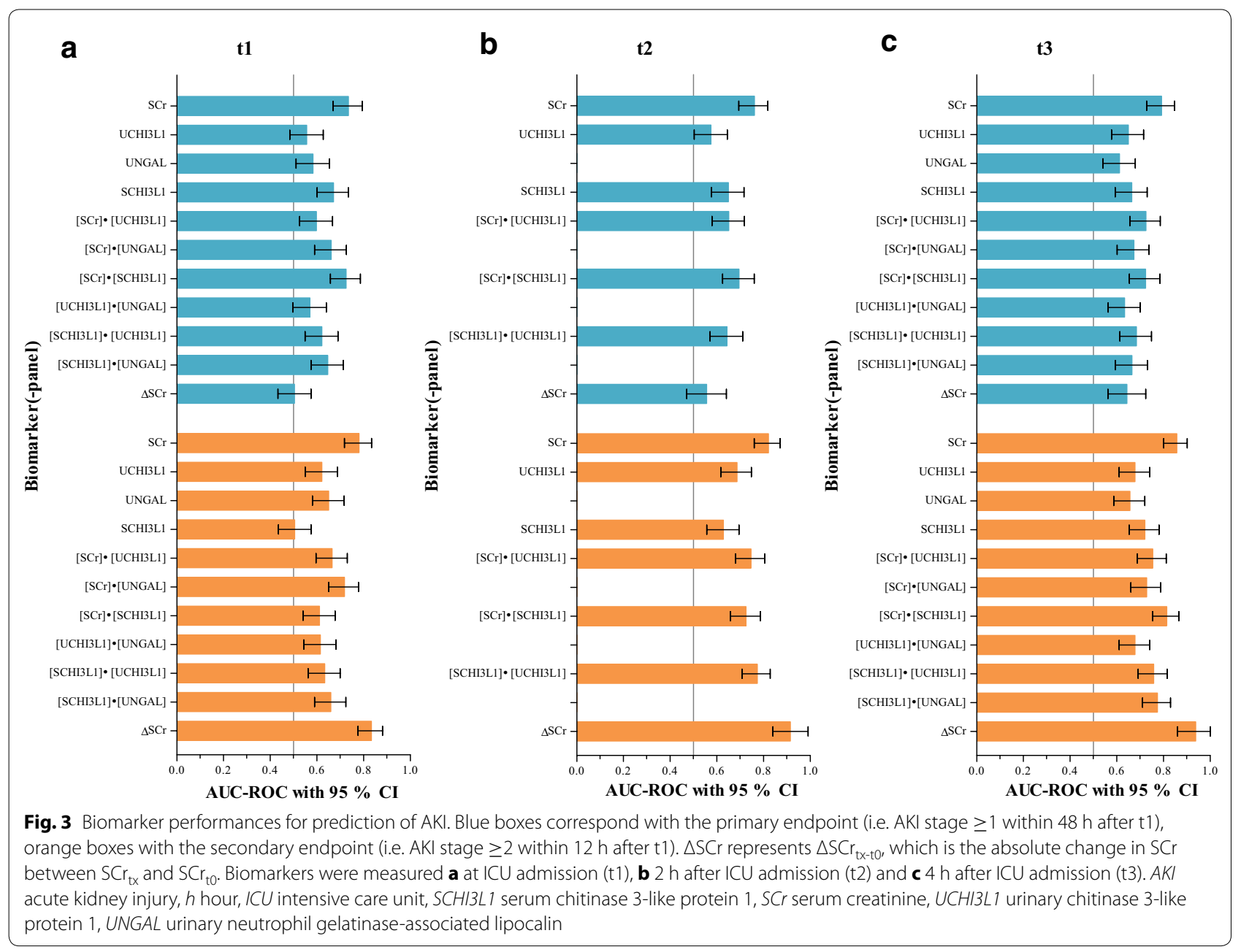

Novel findings of our study are the good to excellent performances of $\Delta \mathrm{SCr}_{\mathrm{t} 1-\mathrm{t} 0}, \Delta \mathrm{SCr}_{\mathrm{t} 2-\mathrm{t} 0}$ and $\Delta \mathrm{SCr}_{\mathrm{t} 3-\mathrm{t} 0}$ for the prediction of AKI stage $\geq 2$ within $12 \mathrm{~h}$ after $\mathrm{t} 1$. In accordance with these results, measurement of very early post-operative $\mathrm{SCr}$ changes, either absolute [10] or relative [32, 33], in adult [10,33] and paediatric [32] cardiac surgery patients has been reported to provide prognostic utility for a subsequent diagnosis of AKI. However, each of these three studies was restricted by some of the following limitations: AKI was not defined according to KDIGO, including oliguric criteria; more severe AKI was not included as endpoint; $\mathrm{SCr}$ was less frequently assessed in the early post-operative period; and AUCROC analysis was not reported.

The simultaneous utilization of functional and damage biomarkers, as in the CSA-NGAL score [26], permits to delineate the spectrum of AKI [34]. In this way $84.6 \%$ of AKI in our specific cohort (i.e. $77 /[77+14]$ ) was classified as AKI without acute tubular damage. The capacity of the kidneys to increase baseline GFR under physiological or pathological kidney stress is described by the renal functional reserve of the glomerular function (Additional file 8: Fig. S6) [35]. In congestive heart failure, CKD and AKI, utilization of the renal functional reserve of the glomerular function allows to replace (in part) the lost function, maintaining a normal whole-organ baseline GFR until $\pm 50 \%$ of the nephrons are nonfunctional. The presence of an intact renal functional reserve of the glomerular function and nephron mass guarantees a low renal frailty or susceptibility [36]. Compared with the general ICU cohort of our previous AKI biomarker study [21], the patients in this study were older (median 70.0 vs. 60.0 y), more often diabetic (median 23.6 vs. $7.2 \%$ ), had a higher BMI (median 27 vs. 24) and a lower baseline eGFR (median 82 vs. $102 \mathrm{ml} / \mathrm{min} / 1.73 \mathrm{~m}^{2}$ ). We therefore hypothesize 
that a lower renal functional reserve of the glomerular function and nephron mass in this population caused the low incidence of both subclinical AKI and AKI with acute tubular damage. This can also explain the inadequate performance of the urinary renal stress or damage biomarkers UCHI3L1 and UNGAL for prediction of AKI stage $\geq 2$ within $12 \mathrm{~h}$ after t1. Our study is, however, not the first to report inadequate diagnostic ability of UNGAL for moderate to severe CSA-AKI [20]. In their multicentre high-risk cohort with $21 \%$ emergent surgeries, $42 \%$ diabetic patients and a baseline eGFR of $67 \mathrm{ml} /$ $\min / 1.73 \mathrm{~m}^{2}$, Parikh et al. reported an AUC-ROC of 0.67 (standard error (SE) 0.04) for the prediction of AKI defined by receipt of RRT or doubling of $\mathrm{SCr}$ [37]. Interestingly, Koyner et al. found an AUC-ROC of 0.88 (95\% CI 0.73-0.99) for the prediction of AKI Acute Kidney Injury Network (AKIN) stage 3 in a cohort comparable to ours [38], indicating the importance of the severity of AKI in the predictive ability of UNGAL.

Our study has several limitations. First, it is limited in being a single-centre study in elective cardiac surgery patients. However, baseline characteristics and the incidence of AKI suggest that our population is representative of cardiac surgery ICUs in developed countries. Second, our study is further limited by the relatively low incidence of AKI stage $\geq 2$ within $12 \mathrm{~h}$ after $\mathrm{t} 1$ (secondary endpoint). Both the fact that we included only elective surgeries and the implemented narrow diagnostic window contribute to this constraint. As such, these biomarker data need to be further validated in larger multicentre prospective studies. Third, we did not measure the panel of G1 cell-cycle arrest biomarkers tissue inhibitor of metalloproteinases 2 (TIMP-2) and insulin-like growth factor-binding protein 7 (IGFBP7) [39], because it was not available at the start of our study.

\section{Conclusions}

In summary, we demonstrated that more frequent assessment of the functional biomarker $\mathrm{SCr}$ in the early postoperative ICU period (first $4 \mathrm{~h}$ ) after elective cardiac surgery in adult patients had good to excellent predictive value for CSA-AKI, indicating that routine $\mathrm{SCr}$ assessment must become more frequent in order to detect AKI more early. We found that AKI was predominantly without acute tubular damage and that subclinical AKI was uncommon in this cohort. This may explain the inadequate predictive value for CSA-AKI of the urinary renal stress or damage biomarkers UCHI3L1 and UNGAL. These results need to be further validated in larger multicentre prospective studies.

\section{Additional files}

Additional file 1: Figure S1. STROBE statement-checklist of items that should be included in the reports of cohort studies (1).

Additional file 2: Figure S2. KDIGO definition and classification of AKI (2).

Additional file 3: Figure S3A.Study course and sample collection times in a fictional morning patient.

Additional file 4: Figure S3B Study course and sample collection times in a fictional afternoon patient.

Additional file 5.Table S1: Data collected in the clinical research file. Table S2: Dilution of serum and urine samples for the initial measurement of CHI3L1 by ELISA. Table S3: Characteristics of the patients and procedures peri-operatively. Table S4A: Biomarker performances at t0 for prediction of AKI. Table S4B: Biomarker performances at $\mathrm{t} 1$ for prediction of AKI. Table S4C: Biomarker performances at t2 for prediction of AKI. Table S4D: Biomarker performances at $t 3$ for prediction of AKI.

Additional file 6: Figure S4 Dissociation of the KDIGO definitions for the diagnosis and staging of AKI by SCr and UO.

Additional file 7: Figure S5. Flow of patients over different diagnostic windows for AKI stage $\geq 2$.

Additional file 8: Figure S6. Renal functional reserve of the glomerular function and functioning nephron mass.

\section{Abbreviations}

CSA-AKI: cardiac surgery-associated acute kidney injury; KDIGO: Kidney Disease|Improving Global Outcomes; RRT: renal replacement therapy; d: day; SCr: serum creatinine; CPB: cardiopulmonary bypass; ECC: extracorporeal circulation; AKS: acute kidney stress; NGAL: neutrophil gelatinase-associated lipocalin; UCHI3L1: urinary chitinase 3-like protein 1; ICU: intensive care unit; STROBE: STrengthening the Reporting of OBservational studies in Epidemiology; UO: urine output; t0: time after the induction of anaesthesia and before the start of surgery; $d_{\text {surgery: }}$ day of surgery; $t 1$ : time of intensive care unit admission; $h$ : hour; $\mathrm{t2}: 2 \mathrm{~h}$ after intensive care unit admission; $\mathrm{t3}: 4 \mathrm{~h}$ after intensive care unit admission; $d_{1 \text { post-op: }}$ first post-operative day; $d_{2 \text { post-oo: }}$ second post-operative day; ELISA: enzyme-linked immunosorbent assay; AUC-ROC: area under the receiver operating characteristics curve; mo: month; eGFR: estimated glomerular filtration rate; CKD-EPI: Chronic Kidney Disease Epidemiology Collaboration; Cl: confidence interval; IQR: interquartile range; BMI: body mass index; DM: diabetes mellitus; EuroSCORE: European system for cardiac operative risk evaluation; SOFA: Sepsis-related Organ Failure Assessment; WBC: white blood cell; CRP: C-reactive protein; LOS: length of stay; SE: standard error; AKIN: Acute Kidney Injury Network; OR: odds ratio; RIFLE: risk, injury, failure, loss and end-stage; HR: hazard ratio; TIMP-2: tissue inhibitor of metalloproteinases 2; IGFBP7: insulin-like growth factor-binding protein 7 .

\section{Authors' contributions}

Design and conduct of the study: EAJH designed the study in conjunction with EM, IH, KF, LN and JDL. EAJH was the Principal Investigator. Data collection: EAJH, IH, KF and AVW enrolled subjects. JDL performed the laboratory analyses and analytically interpreted the results in conjunction with EM. EAJH, $J \mathrm{DL}, \mathrm{IH}, \mathrm{KF}$ and AVW clinically interpreted the data. Management: clinical data were partly managed by JDL and AVW, under supervision of EAJH. Statistical analysis: JDL and EAJH performed the statistical analysis for the study. Interpretation of the data: all authors reviewed the data and participated in discussions related to interpretation. Preparation, review or approval of the manuscript: JDL wrote the paper. All authors read and approved the final manuscript.

\section{Author details}

${ }^{1}$ Laboratory of Biochemistry, Department of Pharmacology, Toxicology and Biochemistry, Faculty of Veterinary Medicine, Ghent University, 
Salisburylaan 133, 9820 Merelbeke, Belgium. ${ }^{2}$ Division of Intensive Care, Department of Internal Medicine, Ghent University Hospital, Faculty of Medicine and Health Sciences, Ghent University, De Pintelaan 185, 9000 Ghent, Belgium. ${ }^{3}$ Division of Cardiac Surgery, Department of Surgery, Ghent University Hospital, Faculty of Medicine and Health Sciences, Ghent University, De Pintelaan 185, 9000 Ghent, Belgium. ${ }^{4}$ Department of Anaesthesiology, General Hospital Sint-Lucas Ghent, Groenebriel 1, 9000 Ghent, Belgium. ${ }^{5}$ Bimetra - Clinical Research Centre Ghent, Ghent University Hospital, Ghent University, De Pintelaan 185, 9000 Ghent, Belgium. ${ }^{6}$ Research Foundation - Flanders, Egmontstraat 5, 1000 Brussels, Belgium.

\section{Acknowledgements}

Special thanks goes to the study coordinators Luc De Crop, Charlotte Clauwaert, Stephanie Bracke and Daisy Vermeiren for their excellent work including screening of patients, collection, processing and freezing of samples, and completing the individual clinical research files, and to Chris Danneels for his IT support. We are grateful to the cardio-anaesthesia team including the physicians Prof. Dr. Stefan De Hert, Prof. Dr. Annelies Moerman, Prof. Dr. Patrick Wouters, Stefaan Bouchez and the anaesthetists in training for asking eligible patients or their legally authorized representatives for consent for this study. Likewise, we are grateful to the post-operative Cardiac Surgery ICU team including the physicians Prof. Dr. Johan Decruyenaere, Harlinde Peperstraete, Joris Vermassen, Wim Vandenberghe and the nursing team, and to the Cardiac Surgery team including the physicians Prof. Dr. Yves Van Belleghem, Thierry Bové, Frank Caes, Thomas Martens, Tine Philipsen and the nursing team. We want to thank Prof. Dr. Joris Delanghe for giving us the opportunity to measure UNGAL concentrations on an automated clinical platform in his laboratory, and Kristel Demeyere and Kevin Van Nuffel for their dedicated help with the determination of CHI3L1 concentrations by ELISA. This translational research was facilitated by Prof. Dr. Sofie Bekaert, coordinator of Bimetra-Clinical Research Centre Ghent. Patent application was facilitated by Dr. Piet De Vos and Dr. Philippe Jacobs of the IP and Licensing Technology Transfer Office of Ghent University Tech Transfer.

\section{Competing interests}

A patent application was filed on 4 April 2011 by Ghent University with EM and Bert Maddens as inventors. The international patent application has been published as WO2012/136548. EAJH received a speaker's fee from Astute Medical and a research grant from Bellco. The remaining authors declare that they have no competing interests.

\section{Availability of data and materials}

The data sets generated during and/or analysed during the current study are available from the co-senior authors EM and EAJH on reasonable request.

\section{Funding}

This work was supported by the Research Foundation-Flanders (FWO, pre-doctoral grant to JDL and postdoctoral grant to EAJH) and the Industrial Research Fund from Ghent University (IOF, advanced Project Ref. F2012/IOFAdvanced/001 with promoters EM and EAJH).

Received: 7 September 2016 Accepted: 24 February 2017 Published online: 01 March 2017

\section{References}

1. Mao H, Katz N, Ariyanon W, Blanca-Martos L, Adybelli Z, Giuliani A, et al. Cardiac surgery-associated acute kidney injury. Cardiorenal Med. 2013;3:178-99.

2. Robert AM, Kramer RS, Dacey LJ, Charlesworth DC, Leavitt BJ, Helm RE, et al. Cardiac surgery-associated acute kidney injury: a comparison of two consensus criteria. Ann Thorac Surg. 2010;90:1939-43.

3. Swaminathan M, Hudson CC, Phillips-Bute BG, Patel UD, Mathew JP, Newman MF, et al. Impact of early renal recovery on survival after cardiac surgery-associated acute kidney injury. Ann Thorac Surg. 2010;89:1098-104.

4. Shlipak MG, Coca SG, Wang Z, Devarajan P, Koyner JL, Patel UD, et al. Presurgical serum cystatin $C$ and risk of acute kidney injury after cardiac surgery. Am J Kidney Dis. 2011;58:366-73.
5. Machado MN, Nakazone MA, Maia LN. Prognostic value of acute kidney injury after cardiac surgery according to kidney disease: improving global outcomes definition and staging (KDIGO) criteria. PLoS ONE. 2014;9:e98028.

6. Reents W, Hilker M, Borgermann J, Albert M, Plotze K, Zacher M, et al. Acute kidney injury after on-pump or off-pump coronary artery bypass grafting in elderly patients. Ann Thorac Surg. 2014;98:9-14.

7. Bastin AJ, Ostermann M, Slack AJ, Diller GP, Finney SJ, Evans TW. Acute kidney injury after cardiac surgery according to risk/injury/failure/loss/ end-stage, acute kidney injury network, and kidney disease: improving global outcomes classifications. J Crit Care. 2013;28:389-96.

8. Kiers HD, van den Boogaard M, Schoenmakers MC, van der Hoeven JG, van Swieten HA, Heemskerk S, et al. Comparison and clinical suitability of eight prediction models for cardiac surgery-related acute kidney injury. Nephrol Dial Transplant. 2013;28:345-51.

9. Lassnigg A, Schmidlin D, Mouhieddine M, Bachmann LM, DrumI W, Bauer $P$, et al. Minimal changes of serum creatinine predict prognosis in patients after cardiothoracic surgery: a prospective cohort study. J Am Soc Nephrol. 2004;15:1597-605.

10. Mcllroy DR, Farkas D, Matto M, Lee HT. Neutrophil gelatinase-associated lipocalin combined with delta serum creatinine provides early risk stratification for adverse outcomes after cardiac surgery: a prospective observational study. Crit Care Med. 2015;43:1043-52.

11. Rosner MH, Okusa MD. Acute kidney injury associated with cardiac surgery. Clin J Am Soc Nephrol. 2006;1:19-32.

12. Bellomo R, Auriemma S, Fabbri A, D'Onofrio A, Katz N, McCullough PA, et al. The pathophysiology of cardiac surgery-associated acute kidney injury (CSA-AKI). Int J Artif Organs. 2008;31:166-78.

13. Rosner MH, Portilla D, Okusa MD. Cardiac surgery as a cause of acute kidney injury: pathogenesis and potential therapies. J Intensive Care Med. 2008;23:3-18.

14. Hoste EA, Cruz DN, Davenport A, Mehta RL, Piccinni P, Tetta C, et al. The epidemiology of cardiac surgery-associated acute kidney injury. Int J Artif Organs. 2008;31:158-65.

15. Katz N, Ronco C. Acute kidney stress - a useful term based on evolution in the understanding of acute kidney injury. Crit Care. 2016;20:23.

16. Vasan RS. Biomarkers of cardiovascular disease: molecular basis and practical considerations. Circulation. 2006;113:2335-62.

17. Haase M, Bellomo R, Haase-Fielitz A. Novel biomarkers, oxidative stress, and the role of labile iron toxicity in cardiopulmonary bypass-associated acute kidney injury. J Am Coll Cardiol. 2010;55:2024-33.

18. Mishra J, Dent C, Tarabishi R, Mitsnefes MM, Ma Q, Kelly C, et al. Neutrophil gelatinase-associated lipocalin (NGAL) as a biomarker for acute renal injury after cardiac surgery. Lancet. 2005;365:1231-8.

19. Haase-Fielitz A, Haase M, Devarajan P. Neutrophil gelatinase-associated lipocalin as a biomarker of acute kidney injury: a critical evaluation of current status. Ann Clin Biochem. 2014;51:335-51.

20. Vandenberghe W, De Loor J, Hoste EA. Diagnosis of cardiac surgeryassociated acute kidney injury from functional to damage biomarkers. Curr Opin Anaesthesiol. 2017;30:66-75.

21. De Loor J, Decruyenaere J, Demeyere K, Nuytinck L, Hoste EA, Meyer E. Urinary chitinase 3-like protein 1 for early diagnosis of acute kidney injury: a prospective cohort study in adult critically ill patients. Crit Care. 2016;20:38

22. Rathcke CN, Vestergaard H. YKL-40—an emerging biomarker in cardiovascular disease and diabetes. Cardiovasc Diabetol. 2009:8:61.

23. Di Rosa M, Distefano G, Zorena K, Malaguarnera L. Chitinases and immunity: ancestral molecules with new functions. Immunobiology. 2016;221:399-411.

24. Vandenbroucke JP, von Elm E, Altman DG, Gotzsche PC, Mulrow CD, Pocock SJ, et al. Strengthening the reporting of observational studies in epidemiology (STROBE): explanation and elaboration. Plos Med. 2007:4:1628-54.

25. Kidney Disease: Improving Global Outcomes (KDIGO) Acute Kidney Injury Work Group. KDIGO clinical practice guideline for acute kidney injury. Kidney Int. 2012;2(Suppl):1-138.

26. de Geus HR, Ronco C, Haase M, Jacob L, Lewington A, Vincent JL. The cardiac surgery-associated neutrophil gelatinase-associated lipocalin (CSA-NGAL) score: a potential tool to monitor acute tubular damage. J Thorac Cardiovasc Surg. 2016;151:1476-81.

27. Devarajan P. Proteomics for biomarker discovery in acute kidney injury. Semin Nephrol. 2007;27:637-51. 
28. Wilson EB. Probable inference, the law of succession, and statistical inference. J Am Stat Assoc. 1927;22:209-12.

29. Newcombe RG. Two-sided confidence intervals for the single proportion: comparison of seven methods. Stat Med. 1998;17:857-72.

30. Chawla LS, Bellomo R, Bihorac A, Goldstein SL, Siew E, Bagshaw SM, et al. Acute kidney disease and renal recovery: guideline report of the acute dialysis quality initiative (ADQI) 16 workgroup. Nat Rev Nephrol. 2017 (in press).

31. Maciel AT, Nassar AP Jr, Vitorio D. Very transient cases of acute kidney injury in the early postoperative period after cardiac surgery: the relevance of more frequent serum creatinine assessment and concomitant urinary biochemistry evaluation. J Cardiothorac Vasc Anesth. 2016;30:56-63.

32. Zappitelli M, Bernier PL, Saczkowski RS, Tchervenkov Cl, Gottesman R, Dancea A, et al. A small post-operative rise in serum creatinine predicts acute kidney injury in children undergoing cardiac surgery. Kidney Int. 2009; 76:885-92

33. Ho J, Reslerova M, Gali B, Nickerson PW, Rush DN, Sood MM, et al. Serum creatinine measurement immediately after cardiac surgery and prediction of acute kidney injury. Am J Kidney Dis. 2012;59:196-201.
34. Murray PT, Mehta RL, Shaw A, Ronco C, Endre Z, Kellum JA, et al. Potential use of biomarkers in acute kidney injury: report and summary of recommendations from the 10th Acute Dialysis Quality Initiative consensus conference. Kidney Int. 2014;85:513-21.

35. Chawla LS, Ronco C. Renal stress testing in the assessment of kidney disease. Kidney Int Rep. 2016;1:57-63.

36. Sharma A, Mucino MJ, Ronco C. Renal functional reserve and renal recovery after acute kidney injury. Nephron Clin Pract. 2014;127:94-100.

37. Parikh CR, Coca SG, Thiessen-Philbrook H, Shlipak MG, Koyner JL, Wang Z, et al. Postoperative biomarkers predict acute kidney injury and poor outcomes after adult cardiac surgery. J Am Soc Nephrol. 2011:22:1748-57.

38. Koyner JL, Vaidya VS, Bennett MR, Ma Q, Worcester E, Akhter SA, et al. Urinary biomarkers in the clinical prognosis and early detection of acute kidney injury. Clin J Am Soc Nephrol. 2010;5:2154-65.

39. Kashani K, Al-Khafaji A, Ardiles T, Artigas A, Bagshaw SM, Bell M, et al. Discovery and validation of cell cycle arrest biomarkers in human acute kidney injury. Crit Care. 2013;17:R25.

40. Eknoyan G, Levin NW. KDOQI clinical practice guidelines for chronic kidney disease: evaluation, classification, and stratification—foreword. Am J Kidney Dis. 2002;39:S14-266.

\section{Submit your manuscript to a SpringerOpen ${ }^{\circ}$ journal and benefit from:}

- Convenient online submission

- Rigorous peer review

Immediate publication on acceptance

- Open access: articles freely available online

- High visibility within the field

- Retaining the copyright to your article 